\title{
A Arqueologia Brasileira da década de 1980 ao início do século XXI:
} uma avaliação histórica e historiográfica*

\author{
JORGE EREMITES DE OLIVEIRA**
}

Resumo: Este artigo analisa a História e a Historiografia da Arqueologia Brasileira da década de 1980 aos dias atuais, indicando suas mudanças, tendências e perspectivas.

Abstract: This paper analyzes the History and the Historiography of the Brazilian Archaeology of the decade from 1980 to the current days, indicating their changes, tendencies and perspectives.

Palavras-chave: Arqueologia brasileira. História da ciência. Historiografia.

Key words: Brazilian archeology. History of the science. Historiography.

"Assiste-se, nos últimos vinte anos, a uma profunda renovação do domínio científico. Não só a maioria das ciências manifesta aquela aceleração da história, que se tornou comum constatar, como também a divisão do saber evolui rapidamente. A reflexão epistemológica - a própria moda do termo 'epistemologia' é significativa - desenvolve-se em extensão e profundidade. Essa comoção atinge, em particular, um conjunto de ciências cujo reconhecimento como entidade científica já é uma novidade considerável: as ciências humanas, como se costuma dizer na França, conforme terminologia universitária consagrada em 1957 (faculdades de letras e ciências humanas), ou as ciências sociais, segundo o uso anglo-saxão" (Jacques Le Goff, 1993, p. 25).

O atual momento por que passa a Arqueologia Brasileira é bastante favorável para um (re)pensar contínuo e permanente so-

* Este artigo é parte revisada e ampliada de um capítulo da tese de doutorado intitulada Da pré-história à história indígena: (re)pensando a Arqueologia e os povos canoeiros do Pantanal, de minha autoria (vide Oliveira, 2002).

** Universidade Federal de Mato Grosso do Sul, Campus de Dourados, Programa de Pós-Graduação em História. Endereço: Caixa Postal 322, Dourados (MS), Brasil, CEP 79825-070. C. Eletrônico: eremites@ceud.ufms.br. 
bre os rumos que a disciplina vem tomando em nosso país, sobretudo para aqueles arqueólogos que seguem ávidos por produzir novos conhecimentos e rever antigos paradigmas e modelos. Esses pesquisadores, muitos dos quais pós-graduados a partir das décadas de 1980 e 1990, vêm recorrendo a novos e mais eficazes aparatos teórico-metodológicos e assumiram uma postura mais crítica frente aos resultados de suas pesquisas. Por isso eles têm sido mais abertos às inovações registradas no âmbito da Arqueologia mundial. Nesta linha de raciocínio, não é demasiado redundante citar Carl-Axel Moberg (1986, p. 21): “Devemos, de fato, ser severos e pessimistas na apreciação dos resultados obtidos por nós próprios (e otimistas quando se trata de enfrentar os projetos)".

Esse tipo de postura remete, inevitavelmente, à tese de que as interpretações teóricas em Arqueologia, assim como em todas as outras áreas do conhecimento, são momentâneas, produtos de uma época, jamais verdades absolutas ou conhecimentos estanques. Ainda que a priori esta idéia possa parecer óbvia, simples ou elementar do ponto de vista filosófico, na prática parece ser uma tendência aparentemente recente na Arqueologia Brasileira, a qual tem tomado força a partir da última década do século XX.

Assumir uma postura pessimista frente aos resultados das investigações arqueológicas não significa adotar um procedimento niilista em análises supostamente críticas, revisionistas ou historiográficas. É, antes de tudo, levar em conta um maior número possível de variáveis e possibilidades interpretativas durante a formulação e a revisão de hipóteses e teses sobre determinados assuntos. Isto também implica, portanto, em tratar de questões relacionadas à própria lógica da dinâmica da pesquisa científica, do processo de acumulação de conhecimentos abordado por Hill (1991), assuntos estes também situados no campo da Filosofia da Ciência. No caso específico da Arqueologia Brasileira, não são poucos os trabalhos que além de apresentarem uma revisão crítica acerca de determinados temas, abordaram os contextos históricos em que as pesquisas foram desenvolvidas. Os diferentes aportes analíticos de Alfredo M. de Souza (1991), Pedro Paulo A. Funari (1992, 1993a, 1993b, 1994a, 1994b, 1998a, 1998b, 1999, 1999/2000), André Prous (1992, 1994), Tania A. Lima (1993), Adriana S. Dias (1994), Gabriela Martin (1996), Johnni Langer (1997a, 1997b), Cristina Barreto $(1998,1999,1999 / 2000)$, Lúcio M. Ferreira (1999, 2001), Tania A. Lima e Regina C. P. da Silva (1999), Maria do Carmo M. M. dos Santos (2001) e Solange N. de Oliveira (2002), dentre outros autores, exemplificam esta possibilidade de análise. 
A proposta defendida não se restringe unicamente a dizer quais foram ou são os pesquisadores que atuaram ou atuam no país, relacionar seus projetos e enumerar suas publicações, quer dizer, fazer uma História historicizante ou factual. Neste artigo, diga-se de passagem, o termo História, grafado com $H$ maiúsculo, refere-se à disciplina e à História que fazem os historiadores (Cardoso e Brignoli, 1990; Cardoso, 1994), cujo conceito apresentado por Marc Bloch (1987, p. 29) em muito se aproxima da compreensão que tenho da própria Arqueologia: "A História é a ciência dos homens no tempo". Isto porque entendo que a Arqueologia é uma ciência social que também estuda as sociedades humanas no tempo, assim como fazem a Antropologia e a História, por exemplo, em seus múltiplos e indissociáveis aspectos sociais, culturais, ecológicos, políticos e econômicos, porém a partir e sobretudo da cultura material por elas produzida. Conseqüentemente, a proposição ora advogada prima por ter uma orientação diferente da de uma História historicizante ou factual; busca ser mais audaciosa, crítica e inicialmente vai ao encontro da seguinte proposta apresentada por Pedro Paulo A. Funari (1994a, p. 25): "O único caminho para entender o desenvolvimento da Arqueologia no Brasil é estudar as relações entre a sociedade e suas mudanças e a prática científica". Tal proposta é polêmica e controversa para muitos, haja vista que pode gerar situações de litígio, principalmente em um país como o nosso, onde parece não estar consolidada a tradição do debate acadêmico que respeita a opinião contrária.

Dito isto e parafraseando R. G. Collingwood, entendo que a História da Arqueologia também serve para o autoconhecimento humano, quer dizer:

"Autoconhecimento, aqui, não significa da natureza corporal do homem, da sua anatomia e da sua fisiologia; nem mesmo um conhecimento da sua mente, na medida em que ela consiste em sensações e emoções; mas sim um conhecimento das suas faculdades de cognição, do seu pensamento ou do seu entendimento da razão" (Collingwood, 1981, p. 257).

Serve ainda para o conhecimento da própria Arqueologia: "Nada nega que a investigação arqueológica está influenciada por diferentes tipos de fatores. No presente, o mais controvertido é o contexto social em que os arqueólogos vivem e trabalham" (Trigger, 1992, p. 23). Dito de outra forma e aproveitando as reflexões de Arruda e Tengarrinha (1999, p. 11), é certo que nenhuma análise reflexiva sobre a produção dos arqueólogos "pode descuidar-se dos circunstanciamentos mais gerais que são também históricos e 
que estabelecem a conexão entre autor-obra-meio, ou seja, a sociedade". Logo, nada mais prudente do que situar as pesquisas arqueológicas no Brasil dentro do momento histórico de sua época, ainda que contrariando um certo pensamento anti-histórico que advoga em favor da neutralidade científica, percebendo os especialistas em Arqueologia como cientistas sociais que não interagem com a sociedade em que vivem.

Mas a análise explicada neste artigo busca ir mais longe: entendo que uma História da Arqueologia também implica em proceder a uma leitura historiográfica dos estudos arqueológicos. É pode ser chamado pelo neologismo científico de Arqueoistoriografia. Ciente de que conceituar é tarefa árdua, embora necessária no campo das ciências sociais, acredito que a Arqueoistoriografia ou Historiografia arqueológica é mais ou menos aquilo que Trigger (1992) considerou como sendo a história do pensamento arqueológico. Nesta perspectiva, cumpre citar o conceito de Historiografia elaborado por Francisco Iglésias:

"No estudo fascinante da História da História, ou melhor, da História da Historiografia - separa-se o processo de desenvolvimento dos povos do seu estudo, seja descrição ou reflexão: aquele é História, este é Historiografia -, vê-se que ela foi sempre objeto de cultivo, em todos os povos e épocas, como se poderia facilmente demonstrar" (Iglésias, 1979, p. 267).

Em outras palavras, a Historiografia é a História da História, ou seja, a História dos estudos históricos, a reflexão que se faz sobre a produção dos historiadores. Este conceito está consagrado no Brasil e compreende dois níveis, um epistemológico e outro da prática social (Lapa, 1981, 1985). Portanto, a Arqueoistoriografia, tal como definida, nada mais é do que a História dos estudos arqueológicos. Esta idéia não é nenhuma novidade na Arqueologia Brasileira. A produção intelectual acerca de temas como préhistória amazônica, Arqueologia oitocentista, Arqueologia Guarani e origens do povoamento humano das Américas e do Brasil, vistos a partir de uma perspectiva histórica e historiográfica, também respaldam minha

\section{O contexto histórico geral do Brasil a partir da década de 1980}

O Brasil das duas últimas décadas do século XX, decênios de crise em termos mundiais (Hobsbawm, 1998), foi marcado por importantes mudanças ocorridas na sociedade nacional como um 
todo. A mais importante transformação pode ser atribuída ao término do regime militar (1964-1985) e ao conseqüente efervescer do processo de redemocratização do país, oficialmente consagrado em 1985, ano em que o Colégio Eleitoral elegeu Tancredo Neves para a Presidência da República. Infelizmente, Tancredo, que foi primeiro-ministro de João Goulart, morreu às vésperas de tomar posse e seu vice, José Sarney, antigo líder da ARENA (Aliança Renovadora Nacional) e ex-presidente do PDS (Partido Democrático Social), agremiações ligadas à ditadura militar, assumiu o governo federal em substituição ao último general presidente, permanecendo no poder por cinco longos anos, de 1985 a 1989 (F. Silva, 1990).

Muitos outros acontecimentos marcaram a vida de milhões de brasileiros entre 1985 e o início da década de 1990: descontrole da inflação e lançamento de planos econômicos para combatê-la; promulgação de uma nova e democrática Constituição Federal (1988); aumento da violência na cidade e no campo; liberdade de imprensa; pluripartidarismo e crescimento de agremiações outrora perseguidas e proibidas pelo regime de exceção; eleição de Fernando Collor de Mello (1989); maior fortalecimento dos movimentos sociais; lançamento do Plano Collor e com ele a apropriação indevida do dinheiro de milhões de contribuintes (1990); ofensiva neoliberal e expansão do processo de globalização; privatização de empresas estatais; etc. Collor de Mello, por sinal, apesar de ter sido o primeiro presidente eleito pelo voto direto desde 1960, o mais votado no acirrado pleito de 1989 , acabou sofrendo um processo de impeachment por corrupção e foi afastado do governo em 1992, ocasião em que Itamar Franco, seu vice, assumiu definitivamente a presidência do país até o final do mandato.

Em 1985, com o fim do regime militar e o início do governo Sarney, eram grandes as expectativas de o país ter uma efetiva política de desenvolvimento econômico com inclusão social, condição fundamental para a consolidação de um regime democrático de fato. Evidentemente que para isso seria necessário, dentre outras ações de governo, uma audaciosa e realista política de investimentos em educação, ciência e tecnologia. Todavia, não foi bem isso o que aconteceu e muitas das expectativas de mudança acabaram frustradas. Esta situação pode ser explicada por múltiplos fatores, inclusive pela própria maneira como o Brasil fez a transição do regime autoritário para a democracia, conforme analisou Boris Fausto: 
"A transição brasileira teve como a espanhola a vantagem de não provocar grandes abalos sociais. Mas teve também a desvantagem de não colocar em questão problemas que iam além da garantia de direitos políticos à população. Seria inadequado dizer que esses problemas nasceram com o regime autoritário. A desigualdade de oportunidades, a ausência de instituições do Estado confiáveis e abertas aos cidadãos, a corrupção, o clientelismo são males arraigados no Brasil. Certamente, esses males não seriam curados da noite para o dia, mas poderiam começar a ser enfrentados no momento crucial da transição. $\mathrm{O}$ fato de que tenha havido um aparente acordo geral pela democracia por parte de quase todos os atores políticos facilitou a continuidade de práticas contrárias a uma verdadeira democracia. Desse modo, o fim do autoritarismo levou o país mais a uma 'situação democrática' do que a um regime democrático consolidado" (Fausto, 1999, p. 527).

Diante do quadro apresentado, a pesquisa científica realizada no Brasil, principalmente a feita nas universidades públicas, continuou enfrentando sérios problemas, muitos deles decorrentes do pouco investimento feito em educação, ciência e tecnologia. Mas a partir de 1990, com o início do governo Collor, a situação ficou ainda mais complicada como bem denunciou Florestan Fernandes em seu artigo Ciência e tecnologia, publicado no jornal Folha de S. Paulo em 5 de março de 1990:

"É terrível acompanhar os mendigos do saber, a peregrinação de cientistas, tecnologistas e professores com as sacolas nas mãos, pedindo verdadeiras esmolas, para que a ciência, a tecnologia e a universidade não sejam reduzidas à estagnação. $\mathrm{O} C \mathrm{CNP}$, a Capes e o Finep (Financiadora de Estudos e Projetos) já não encontram um respiro para sobreviver. A Representação Nacional dos Pró-Reitores de Pesquisa e Pós-Graduação das Universidades Brasileiras (em 19$20 / 11 / 89$ ) e a Sociedade Brasileira para o Progresso da Ciência $(23 / 11 / 89)$ levaram aos parlamentares os últimos gemidos de um sistema da ciência que está sendo destruído deliberada e metodicamente. O dinheiro público flui em várias direções, da corrupção organizada à dissipada pela incompetência e à rotina burocrática imperturbável. Ninguém se comove! Até quando? Pode uma nação ser unificada, independente e próspera aniquilando o uso racional do talento? No instante, a palavra está com os eleitores. Adiante, as decisões terão de ser tomadas em nossas mãos. Se não fizermos isso, seremos cúmplices de um crime irreparável, pela omissão ou pela tolerância barata" (Fernandes, 1990, p. 207).

Um mês depois (9-4-1990), no artigo A pesquisa ameaçada, também publicado na Folha de S. Paulo, novamente Florestan Fernandes tratou do assunto: 
"O governo incluiu a educação, a produção científica, a criação artística e a capacitação tecnológica no âmbito de medidas provisórias e de decretos-lei traumáticos. A promessa de 'modernização' concretiza-se como um pesadelo, com afoiteza, desconhecimento do valor intrínseco de muitas entidades essenciais, que exigiam renovação, mas foram destruídas ou inviabilizadas, incompetência na avaliação de suas contribuições insubstituíveis e das funções do Estado (que não podem ser anuladas pela sucessão dos governos) no fenômeno da educação, da pesquisa científica, da cultura sob todas as suas formas e da inovação tecnológica. Além disso, medidas provisórias e decretos, que aparentam conformar-se à Constituição e às leis vigentes, transgridem-nas afrontosamente, convertendo-se em casuísmos chocantes. O governo coloca-se acima da lei e provoca o desbaratamento de uma herança histórica penosamente acumulada" (Fernandes, 1990, p. 204).

Em fins da década de 1980 e início da de 1990, portanto, a pesquisa no Brasil passou a enfrentar mais uma crise. As universidades públicas, por exemplo, embora há muito sendo as principais instituições de pesquisa e de ensino superior do país (Bosi, 2000), foram bastante prejudicadas em suas atividades fins, sobretudo durante o governo Collor. Mas o momento foi ainda mais árduo para os setores populares da sociedade, aqueles que historicamente vêm sendo os mais penalizados em épocas difíceis.

\section{O surgimento de uma nova geração de arqueólogos brasileiros}

Uma das características mais marcantes da Arqueologia Brasileira a partir da década de 1980 é o surgimento de uma nova geração de arqueólogos brasileiros, uma força acadêmica que apesar de não ser maioria no início, paulatina e progressivamente passou a renovar e influenciar as pesquisas arqueológicas realizadas em todo o território nacional'.

Para tanto, foi preciso estar aberta aos avanços mais recentes registrados na Arqueologia mundial e seguir novos caminhos: optar por outros aportes teórico-metodológicos, estudar novos objetos, rever antigos problemas (e apresentar outros novos), analisar velhos paradigmas e modelos, utilizar novas abordagens e assumir uma postura mais crítica frente aos resultados de suas investigações. Isso

Usar o termo nova geração de arqué́logos não implica, necessariamente, em valer-se de um raciocínio maniqueísta que busca simplificar a discussão em pauta, limitando-a em uma aparente dicotomia entre novos e velhos arqueólogos brasileiros, leitura esta que empobrece e distorce a discussão em pauta. 
somente foi possível quando alguns arqueólogos passaram a ser mestres de si mesmos, isto é, quando efetivamente tiveram liberdade, autonomia e recursos para criar e ensinar algo diferente do que então predominava dentro da academia e de outras instituições de pesquisa. Tamanha ousadia custou caro para alguns pioneiros dessa nova geração, os quais tiveram de enfrentar diversas intempéries políticas, inclusive algumas perseguições dentro de suas próprias instituições de trabalho.

A inauguração de cursos de pós-graduação stricto sensu, espaços reservados a mestrados e doutorados em Antropologia, Arqueologia, História e áreas afins, também foi de suma importância para o desenvolvimento dos estudos arqueológicos no Brasil. Tal necessidade já havia sido apontada nas Diretrizes para a Arqueologia Brasileira: Documento de Santa Cruz do Sul (Sociedade de Arqueologia Brasileira, 1989), manifesto aprovado em 1989, durante a V Reunião Científica da Sociedade de Arqueologia Brasileira, realizada na cidade gaúcha de Santa Cruz do Sul. Este documento também foi pensado a partir do célebre artigo Arqueologia Brasileira: algumas considerações, de Walter A. Neves (1988 [1989]).

Via de regra esses cursos passaram a contribuir substancialmente para a produção e a socialização de novos conhecimentos, criando uma atmosfera de profícuos debates e reflexões teóricometodológicas. Gradualmente foram surgindo algumas condições necessárias para dar início a um processo de renovação da disciplina arqueológica no país, resultado de um certo amadurecimento epistemológico gerador de mudanças de nuance, mais ou menos de acordo com o que o próprio W. Neves (1988) havia pensado em fins da década de 1980 .

Exemplo disso foi a criação, em 1992, de uma área de concentração em Arqueologia no Programa de Pós-graduação em História da Pontifícia Universidade Católica do Rio Grande do Sul (PUCRS), sediada em Porto Alegre, um marco na história da Arqueologia Brasileira, sobretudo para a região Sul do país (ver Kern, 1994, 2000a, 2000b). Antes disso, em 1990 teve início na Universidade de São Paulo (USP), mais precisamente no Museu de Arqueologia e Etnologia (MAE), o primeiro curso de pós-graduação stricto sensu em Arqueologia inaugurado no país. Dissertações de mestrado e teses de doutorado ainda vêm sendo defendidas em outras universidades brasileiras, principalmente na Universidade Estadual de Campinas (UNICAMP), Universidade Federal de Pernambuco (UFPE) e Universidade Federal do Rio de Janeiro (UFRJ), dentre outras, bem como no exterior, "ainda que muito ainda esteja inédito e que poucos trabalhos se aventurem a questionamentos teóricos mais amplos" (Funari, 1998b, p. 22; ver também Prous, 1994, p. 13-15). 
Acrescentam-se ainda os impactos positivos causados pelo acelerado desenvolvimento da Informática e a revolução causada pela Internet, a rede mundial de computadores, a partir da década de 1990: acesso cada vez fácil e mais rápido às informações e intensificação da comunicação entre pesquisadores e instituições. Um bom exemplo disso é o sítio eletrônico da Equipe Naya (www.naya.org.ar), da Argentina, um espaço virtual destinado à Antropologia e à Arqueologia, inclusive para a realização de congressos virtuais contando com a participação de especialistas de vários países do mundo, a maioria da América Latina.

Apesar disso tudo, é importante salientar que esse período mais recente ainda não foi alvo de pesquisas exaustivas no âmbito da História e da Arqueoistoriografia. Há, todavia, alguns trabalhos reflexivos que o analisam em alguns aspectos.

Ainda na década de 1980, Betty Jane Meggers, quem juntamente com Clifford Evans elaborou e coordenou o PRONAPA (1965-1970), percebeu o surgimento de um novo momento na Arqueologia Brasileira e assim o avaliou:

"Em 1980, a Arqueologia Brasileira chegou à maturidade com a fundação da Sociedade de Arqueologia Brasileira (SAB). Em 1982, tinha mais de 100 membros representando mais de 20 instituições. As reuniões realizadas em 1981 no Rio de Janeiro e em 1983 em Belo Horizonte, tiveram a participação de profissionais e estudantes de todas as partes do país. [...] Ampliar oportunidades de treinamento acadêmico é um desafio que deve ser concretizado a fim de se formar pessoal necessário para conduzir os programas de salvamento, assim como realizar outras investigações para preencher as lacunas de nosso conhecimento sobre o desenvolvimento cultural durante os tempos pré-europeus. A dedicação e a perseverança que caracterizam os esforços durante os 50 anos passados, tornam possível predizer que os obstáculos serão superados e contribuições significativas ao método, à teoria e ao conhecimento arqueológico serão feitas por arqueólogos brasileiros nos anos que estão por vir" (Meggers, 1987a, p. 154).

Alguns anos depois, já na década de 1990, Pedro Paulo A. Funari (1989, 1994a, 1994b, 1998b, 1999 e outros), sob outro ponto de vista, publicou vários artigos analisando a trajetória e os rumos da Arqueologia no Brasil. Segundo ele, durante o regime militar houve a conquista de um significativo espaço institucional para a Arqueologia Brasileira, fato este que também está associado à constituição de um establishment ou poder estabelecido arqueológi-

Artigo originalmente publicado na revista American Antiquity (ver Meggers, 1985). 
co, quer dizer, à formação de um grupo de pessoas em posição de poder e autoridade que passou a controlar e influenciar a Arqueologia em várias regiões do país, mantendo-se pouco aberto à inovação ou renovação. Na opinião do autor, o marco histórico inicial teria sido o próprio desenvolvimento do PRONAPA (1965-1970) e a ação de muitos de seus seguidores, não raramente reconhecidos como pronapianos ou pronapistas, adjetivos às vezes usados em tom pejorativo, embora aqui não os esteja fazendo com essa conotação. Sendo um establishment arqueológico, obviamente que trouxe em seu bojo relações com o saber e o poder, incluindo o micropoder. Tais relações vêm ocorrendo em instituições universitárias, agências de fomento às atividades de pesquisa e editoras, dentre outros espaços institucionais e burocráticos, públicos ou privados, onde não raramente há conflitos de interesses, inclusive entre diferentes gerações de pesquisadores ou entre profissionais que defendem pontos de vista divergentes sobre determinados assuntos.

A avaliação feita por Funari continua sendo bastante polêmica e tem sido formalmente contestada por um certo número expressivo de arqueólogos, principalmente pelos que adotaram a proposta histórico-culturalista do PRONAPA, paradigma pertinente para a época, haja vista que teve no clássico Method and theory in American Archaeology, de Gordon R. Willey \& Philip Phillips (1958), uma importante referência teórico-metodológica, uma obra que "deitou raízes profundas na arqueologia brasileira, dos anos 60 em diante" (Lima, 2000 [1997], p. 1; ver também Lyman et al., 1997). Contudo, na década de 1970 começou a haver um distanciamento da Arqueologia Brasileira em relação aos "avanços que a disciplina vinha fazendo no exterior" (Lima, 2000, p. 2), sobretudo quanto as inovações apresentadas pela Nova Arqueologia ou Arqueologia Processual iniciada na década de 1960 nos Estados Unidos.

Acredito que a polêmica maior está na associação do PRONAPA, sobretudo na de seus coordenadores (Betty Jane Meggers e Clifford Evans), à origem do establishment arqueológico nacional. Neste sentido, parte do artigo A contribuição de Betty Meggers para a Arqueologia Pré-histórica da América do Sul, escrito por Ondemar Dias Júnior, arqueólogo que participou do PRONAPA, serve de contraponto a muitas críticas que os pronapianos têm recebido:

"Nem sempre, no entanto, as críticas se fizeram com a ética recomendada e dentro dos procedimentos normais da vida acadêmica. Mesmo no nosso país, algumas pessoas - poucas, felizmente - que desconhecem as mais elementares regras do respeito acadêmico, 
que muito pouco ou quase nada podem apresentar de produção que as credencie, plenas de uma autocapacitação no mínimo duvidosa, fugindo às perspectivas saudáveis do debate, especializaram-se em detratar seu trabalho [de Betty Jane Meggers], divulgando fatos caluniosos, sem a menor pretensão de prová-los. São verdadeiros vampiros da excelência científica alheia, que por não a possuírem, aproveitam-se de quem as tem ao longo de uma vida de trabalho sério e respeitado, deleitando-se em publicar textos obscuros e de má leitura, para se tornarem, pelo menos, conhecidos. E conseguem. Não exatamente da forma que imaginam, mas conseguem [...]" (Dias Júnior, 1997, p. 8).

A dura crítica apresentada por Dias Júnior, ainda que feita sob forma de desabafo, não parece ter sido dirigida a Pedro Paulo A. Funari, haja vista a vasta produção que ele acumulou entre 1988 e o primeiro semestre de 2001, incluindo doze livros escritos ou organizados, três monografias, mais de uma centena de artigos e resenhas, além da tradução e revisão de vários trabalhos (ver Funari, 2001). Na opinião de muitos arqueólogos brasileiros e estrangeiros, como Johnni Langer (1997a, p. 112), Funari é um dos grandes teóricos da atualidade na Arqueologia Brasileira, alguém que tem conquistado reconhecimento nacional e internacional através de muitos ensaios publicados em vários países americanos e europeus.

Betty Jane Meggers e Clifford Evans, por sua vez, possuem uma longa folha de serviços prestados no Brasil e em países como Argentina, Costa Rica, Cuba, Equador, México, Peru, Venezuela e outros, de onde têm recebido várias homenagens e títulos honoríficos pela dedicação científica e pelo interesse em desenvolver a Arqueologia Latino-americana. Na verdade, Meggers e Evans foram os arqueólogos estrangeiros que mais contribuíram para desenvolvimento da Arqueologia Brasileira (Meggers ainda continua apoiando vários projetos desenvolvidos no país). Por isso acredito ser relevante citar as palavras de Luis G. Lumbreras, arqueólogo peruano de orientação marxista que participou do Segundo Simpósio Comemorativo ao Quinto Centenário, realizado em Washington, na Smithsonian Institution, em outubro de 1998:

"Não posso deixar passar esta ocasião para assinalar nossa comum homenagem aos amigos e mestres [Clifford Evans e Betty J. Meggers], os quais foram solidários conosco à margem de ideologias ou tendências, sem reclamar conseqüência nem reciprocidade nenhuma. Aqui estamos reunidos por este vínculo comum; militamos em distintas posições teóricas, praticamos dissimiles formas de fazer Arqueologia e nossa única retribuição é e tem sido a de trabalhar pelo desenvolvimento de nossa disciplina, com independência de critério e ação" (Lumbreras, 1992, p. 30). 
A origem de toda essa controvérsia parece ter forte associação com os debates travados entre Betty Jane Meggers e Anna Curtenius Roosevelt, ambas arqueólogas estadunidenses especializadas em Arqueologia Amazônica. As discussões iniciaram em meados da década de 1980 e também estão relacionados à defesa de teses divergentes sobre a pré-história daquela região sul-americana. Grande parte dos debates e a bibliografia sobre o assunto foram publicados em português e castelhano, como pode ser conferido nos trabalhos de Meggers (1987b, 1998a, 1998b, 1999) e Roosevelt (1991, 1992, 1999), e ainda em (Lathrap, 1975), W. Neves (1989, 1991) e E. Neves (1999a, 1999/2000).

Segundo consta na História da Arqueologia Brasileira (A. Souza, 1991), o PRONAPA contou com a participação dos seguintes arqueólogos brasileiros:

"Eurico T. Miller, José Proenza Brochado, Walter F. Piazza, José Wilson Rauth, Igor Chmyz, Fernando Altenfelder Silva, Ondemar Ferreira Dias Jr., Valentim Calderón, Nássaro A. de Souza Nasser e Mário Ferreira Simões. Já no segundo ano, Altenfelder se afastaria, entrando Sílvia Maranca e Celso Perota" (A. Souza, 1991, p. 114-115).

Outros profissionais, todavia, adotaram a orientação históricoculturalista do programa e seguiram trabalhando em várias regiões do país, a exemplo do arqueólogo jesuíta Pedro Ignacio Schmitz, diretor do Instituto Anchietano de Pesquisas (IAP), sediado em São Leopoldo, Rio Grande do Sul, uma das principais instituições brasileiras de pesquisa arqueológica.

Somente na década de 1980, o enfoque processualista começou a ser usado no Brasil, principalmente em alguns estudos apresentados como dissertações e teses acadêmicas, conforme consta na bibliografia arrolada por Kipnis et al. (1994/1995), mais uma prova da importância dos cursos de pós-graduação stricto sensu para renovação da Arqueologia no país. Há também de se registrar as influências que a Arqueologia Brasileira têm recebido de escolas arqueológicas em voga na Europa, sobretudo na França, as quais também têm marcado as pesquisas desenvolvidas em algumas regiões do país, a exemplo do Nordeste. Hoje em dia, portanto, a avaliação feita por Arno A. Kern ao tratar dos jovens historiadores brasileiros também é válida para os jovens arqueólogos, pois nesses espaços institucionais eles

“[...] são desde cedo estimulados a sair de sua escuta passiva, a participar dos debates suscitados, a discutir os textos de outros historiadores, a sistematizar e organizar seus conhecimentos, a desenvolver suas capacidades de sínteses ao produzir suas próprias monografias e dissertações" (Kern, 2000b, p. 10). 
Embora não desconheça que um regime militar seja a "intervenção de uma força que age com determinada eficácia, sempre relativa na medida em que isto se dá em um campo de forças" (Vetho, 1984, p. 241), penso que a tese do establishment arqueológico merece, por si só, novas interpretações e estudos mais acurados. Uma investigação desse tipo, no campo da História e da Arqueoistoriografia, não pode ter como principal foco de análise o PRONAPA e seus seguidores, ainda que, como bem salientou A. Souza (1991, p. 114), a implantação desse programa não tenha sido pacífica. Digo isto porque talvez existam outras forças políticas de maior peso que os pronapianos, as quais há muito continuam atuando quase que totalmente incólumes a qualquer tipo de crítica. Nesta linha de raciocínio, a avaliação feita pelo jornalista Marcelo Leite (2000, p. 5), autor da matéria A falha arqueológica do Brasil, publicada na Folha de S. Paulo em 19/2/2000, serve de adendo e não pode ser ignorada: "Autoritarismo é uma qualificação corriqueira, quando se trata de caracterizar esse campo acadêmico, que só vingou depois da Segunda Guerra".

Polêmicas à parte, uma constatação deve ser feita: o passado e o presente da Arqueologia Brasileira deve ser reinterpretado permanentemente, o que às vezes pode exigir o rompimento com determinados pactos consensuais, tipos variados de álibis ideológicos e propostas de triagem de assuntos.

Acreditando, porém, na pertinência da tese do establishment arqueológico, ainda que com as ponderações apresentadas, suponho que ela tenha validade para o caso de profissionais que por décadas permaneceram fechados à pluralidade epistemológica e aos avanços científicos registrados na Arqueologia mundial, não raramente reagindo de forma concatenada, como grupos sociais, contra quem o fizesse. Isso denota, dentre outras coisas, uma explícita forma de dominação no campo da produção científica. Daí entender, por exemplo, o fato de W. Neves $(1999 / 2000$ b, p. 8$)$ ter recentemente assinalado a "predominância de uma certa resistência no establishment da arqueologia brasileira ao pensamento crítico". Sem embargo à sua postura, não disponho de dados para associar esta situação a um grupo específico de arqueológicos que vem atuando no território nacional. Avalio, porém, que os pronapianos não devem ser o principal alvo de análises desta natureza, até porque não estiveram/estão presentes em todas as regiões e instituições de um país da dimensão que tem o Brasil.

Ainda sobre o debate em torno da tese do establishment arqueológico, apresento duas citações que explicam a leitura que Funari tem feito sobre o assunto. A primeira deixa claro que não 
existe neutralidade científica em Arqueologia e que ela, por sua vez, está inserida em contextos sociopolíticos que marcam a dinâmica da vida em sociedade:

"Na medida em que a Arqueologia é uma disciplina científica, possui lugares institucionais de pesquisa que controlam ao menos seis questões básicas: o que deve ou não ser pesquisado, o acesso aos sítios arqueológicos, ao material armazenado, às verbas de pesquisa, aos cargos acadêmicos e aos meios de informação científica encarregados de divulgar os resultados do estudo arqueológico" (Funari, 1988, p. 75).

\section{Finaliza:}

"Tudo isto se baseia numa rígida hierarquia, no interior das instituições acadêmicas, que estabelece a legitimidade científica dos projetos de pesquisa. Daí que os critérios político-ideológicos por detrás de cada pesquisa, de cada ascensão ou estagnação acadêmica, sejam sempre apresentados, pelos detentores do 'poder arqueológico' como critérios de ordem epistemológica, portanto exteriores ao domínio do conflito social, incontestáveis. As discordâncias de fundo sociopolítico apresentam-se transformadas numa disputa entre a ciência, apanágio dos que detêm o poder institucional, e a suposta incompetência de quem defende certas posições práticas e metodológicas que lhes são contrárias. No entanto, em sociedades compostas por grupos em conflito, a hegemonia de uma legitimidade encontrase sempre sujeita ao confronto com outras legitimidades, originárias de outros interesses sociopolíticos. Os embates epistemológicos e acadêmicos - retirada a ilusória capa de 'objetividade do arqueólogo' - remetem ao inevitável posicionamento e comprometimento do arqueólogo perante a sociedade e à tomada de consciência da sua decorrente responsabilidade" (Funari, 1988, p. 76).

A segunda, por seu turno, contextualiza a trajetória da Arqueologia Brasileira pós-1964, inserindo-a no contexto das transformações ocorridas na sociedade nacional como um todo:

"A Arqueologia vem se desenvolvendo no Brasil há muito tempo e sua história, aqui, dependeu muito das transformações da sociedade brasileira como um todo. O recente governo militar produziu um establishment arqueológico impermeável a mudanças e incapaz de se afirmar fora do país e face às outras Ciências Humanas no Brasil. Entretanto, recentes desenvolvimentos estão mudando este quadro e as enormes áreas abertas aos pesquisadores interessados numa redefinição da Arqueologia brasileira e dos estudos de cultura material oferecem oportunidades únicas para estudiosos ousados. Particularmente auspicioso é o fato de que uma nova geração de estudantes e especialistas está propensa a mudar: a leitura de trabalhos teóricos e interpre- 
tativos está forçando uma abordagem pluralista da Arqueologia. Felizmente, estes estudiosos não podem ser dispensados como grupos marginais uma vez que eles se constituem nos únicos arqueólogos habilitados a fazer face seja a seus colegas arqueólogos estrangeiros, seja a seus colegas das Ciências Humanas e Socais no Brasil. Além disso, a Arqueologia está sendo praticada de forma erudita em diferentes instituições e há um crescente interesse numa abordagem crítica da cultura material" (Funari, 1994a, p. 37; 1999, p. 31-32).

Outros trabalhos há pouco publicados têm igualmente enfatizado o surgimento de uma nova geração na Arqueologia Brasileira, embora a maioria não trate especificamente do mencionado establishment. Uma exceção parece ser o artigo de Cristina Barreto (1999), apresentado na I Reunião Internacional de Teoria Arqueológica na América do Sul, realizada na cidade de Vitória, Espírito Santo, em 1998, por ocasião da 21ª Reunião da Associação Brasileira de Antropologia, no qual a autora teceu críticas ao trabalho analítico que Funari tem realizado sobre a Arqueologia Brasileira, afirmando que

"[...] apesar de reconhecer a importância da teoria na arqueologia, trabalhando contra a dificuldade que ele mesmo admite em mapear seus contornos em contexto brasileiro, é marcado por uma preocupação doutrinária em identificar agendas políticas e ideológicas no discurso de determinados grupos na história da arqueologia brasileira, sem no entanto explorar a fundo as teorias em torno das quais estes grupos organizaram sua produção científica, e tampouco analisa os efeitos desta produção para a construção de um passado arqueológico nacional" (Barreto, 1999, p. 203).

Em referência a um outro trabalho de sua autoria (Barreto, 1998), a arqueóloga prosseguiu apresentando sua avaliação sobre o desenvolvimento da Arqueologia Brasileira nas décadas de 1960 e 1970:

"Enquanto nas ciências sociais grupos representativos da intelectualidade brasileira se posicionavam abertamente contra o regime militar, os arqueólogos, via de regra, parecem ter ficado à margem dos eventos tanto de engajamento político aberto, como da censura e repressão política que recaíram sobre as universidades brasileiras neste período. Neste sentido, é falsa qualquer tentativa de caracterizar uma politização da disciplina para este período como faz Funari (1992). Ao contrário, pode se dizer que a arqueologia foi até mesmo um pouco rejeitada pelas ciências sociais, justamente por não contar com um quadro teórico compatível com as teorias e ideologias de esquerda da época e por não participar no engajamento político tão típico dos intelectuais brasileiros de então" (Barreto, 1999, p. 206). 
Cristina Barreto rechaçou parte das idéias defendidas por Funari, também avaliando como falsa a tese da origem do establishment arqueológico diretamente associada ao PRONAPA (décadas de 1960 e 1970). Considerou ainda superficial a análise que o autor fez sobre o uso de teorias por parte de determinados grupos de arqueólogos brasileiros, embora ela mesma não tenha feito uma discussão mais detalhada sobre o assunto, ou seja, acerca da relação entre Arqueologia Brasileira e o contexto econômico, político e sociocultural do país. Para S. Oliveira (2002, p. 55), em recente dissertação de mestrado: "Barreto preocupa-se mais com questões metodológicas do que propriamente teóricas. Isto fica evidente em suas críticas à teoria arqueológica nascente no Brasil".

Em uma outra publicação, Barreto falou do surgimento de uma nova geração de arqueólogos brasileiros, a segunda:

“[...] a partir dos anos 1980, o aparecimento de uma segunda geração de arqueólogos brasileiros, agora não só com formação acadêmica especializada no Brasil e no exterior, mas também com projetos teóricos mais bem definidos, começou a mudar o tipo de arqueologia feita no país. Reflexos de uma arqueologia anglo-saxônica, mais dedutiva e orientada por problemas específicos em busca da formulação de modelos e tendências, chegaram ao país, não sem o atraso típico de países marginais e a resistência de gerações anteriores" (Barreto, 1999/2000, p. 46).

Pedro Ignacio Schmitz, por sua vez, alguns anos antes mesmo de Barreto, associou o surgimento dessa nova geração a influências da Nova Arqueologia:

"Influências americanas da era da Nova Arqueologia chegam cada vez mais fortes com os cursos de pós-graduação e são o equipamento dos novos doutores e bacharéis (licenciados) das universidades. Estes grupos são identificados como uma nova geração de arqueólogos" (Schmitz, 1994, p. 27).

Ainda que toda periodização seja arbitrária, é fato que esse novo momento da Arqueologia Brasileira não está descontextualizado de sua época, tampouco surgiu do nada. Teve início durante o processo de redemocratização do país, bem como da consolidação e crescimento da institucionalização da pesquisa arqueológica em muitos Estados da federação, principalmente nas regiões Sudeste e Sul, maiores centros formadores de arqueólogos. Evidentemente que herdou as contribuições dadas pelas gerações anteriores, em especial aquela profissionalizada nas décadas de 1960 e 1970 , das quais apenas uma parte foi influenciada pela proposta teórico-metodológica do PRONAPA. 
Mas isso não é tudo. Com o processo de redemocratização do país, jovens arqueólogos passaram a adotar uma postura de maior engajamento social, distanciando-se ainda mais da geração anterior. Para André Prous (1994, p. 24), um exemplo desse engajamento está na aproximação da nova geração em relação à militância em defesa dos direitos dos povos indígenas, "dos quais sente cada vez mais próxima pela tendência da Etnoarqueologia".

Do ponto de vista epistemológico, essa situação talvez possa ser explicada por eventuais anomalias surgidas da acumulação de conhecimentos produzidos pelas gerações anteriores (Meltzer, 1979), em sua heterogeneidade, o que acabou gerando uma crise de paradigmas, condição favorável para o surgimento e a aceitação de novas referências teórico-metodológicas para a comunidade arqueológica do Brasil. Igualmente não há como dissociar esse novo momento do processo de renovação das ciências sociais no país (Antropologia, Ciência Política, Geografia, História, Sociologia etc.), pois como disse Octávio Ianni (1992, p. 34), "a marcha da sociedade continua a criar e recriar novas realidades". Entretanto, de um modo geral a Arqueologia no Brasil parece não estar muito informada sobre o desenvolvimento das demais ciências sociais no país (ver Reis et al., 1997), embora o contrário - e com mais intensidade ainda - também seja verdadeiro.

A despeito do transcurso das teorias arqueológicas, não tenho dúvidas de que a partir da década de 1980 e principalmente da de 1990 a Arqueologia Brasileira gradativamente começou a mudar e essa mudança continua em curso. Em 1995, por exemplo, durante a VIII Reunião Científica da Sociedade de Arqueologia Brasileira, realizada em Porto Alegre, Tania A. Lima fez a seguinte colocação:

"Neste conturbado fim de século, ou mais precisamente fim de milênio, em que nós estamos assistindo, perplexos, a mudanças que se processam em ritmos cada vez mais vertiginosos, cabe indagar, no antepenúltimo encontro da Sociedade de Arqueologia Brasileira antes da virada, como anda a arqueologia neste momento, no Brasil e no mundo, e que possíveis rumos ela deve tomar.

Nós diríamos que ela está começando a emergir da efervescência dos debates dos anos 80 , introduzidos pelo que se convencionou chamar de pós-processualismo, movimento fortemente inspirado no clima intelectual pós-moderno que se instalou na década passada e que continua no centro das atenções até hoje" (Lima, 1995/1996, p. 227). 
Na IX Reunião Científica da Sociedade de Arqueologia Brasileira, ocorrida no Rio de Janeiro em 1997, a penúltima do século XX e uma das mais profícuas então realizadas, a arqueóloga novamente expôs um interessante panorama das teorias arqueológicas no Brasil, apresentando críticas pontuais:

"Vista em seu conjunto, a arqueologia brasileira permanece ainda hoje fortemente atada ao histórico-culturalismo e continua obstinadamente apegada a princípios e procedimentos que o mundo há muito sepultou. Isolada, é vista por outros países da América do Sul e também da América do Norte como fechada em si mesma, na medida em que nossa produção é pouco divulgada, sendo praticamente desconhecida no exterior" (Lima, 2000, p. 3).

\section{Conclui:}

"Esta brevíssima e sumária exposição da trajetória da teoria na arqueologia brasileira permite constatar que fizemos um grande investimento em teorias de baixo nível, ou seja, em generalizações empíricas sobre o registro arqueológico, privilegiando a elaboração de tipologias, seriações e construções de quadros espaço-temporais. Não se desmerece aqui a validade desses procedimentos, justificáveis e necessários, mas sim a sua adoção como um fim em si, ignorando e recusando a incorporação de reflexões feitas ao longo de três décadas. Como conseqüência direta, o imprescindível movimento seqüencial em direção às teorias de nível médio e alto foi por muito tempo abortado, empobrecendo extraordinariamente a disciplina em nosso país" (Lima, 2000, p. 4).

Na mesma ocasião, Emílio Fogaça fez a seguinte leitura da trajetória das teorias arqueológicas no país:

"A arqueologia brasileira - aquela que, graças ao Programa Nacional de Pesquisas Arqueológicas, ocupou extensivamente espaço institucional nas três últimas - caracteriza-se mais como um corpo pragmático baseado numa metodologia apriorística do que como resultado da participação influente nos debates da arqueologia internacional. Ainda que, na concepção do Programa, uma certa postura teórica norte-americana foi fundamental, todas as discussões aconteceram em torno da criação de tipologias espaço-temporais e, por conseguinte, esse período vem sendo estigmatizado como 'descritivo', 'classificatório', com um acento pejorativo raramente empregado pelas arqueologias ao norte do Equador em relação aos pioneiros" (Fogaça, 2000, p. 3-4).

A colocação feita por Fogaça é bastante ponderada, de certa maneira sensata do ponto de vista histórico e arqueoistoriográfico, mas apresenta uma situação de enclave diante de um quase inevi- 
tável conflito de gerações: de um lado, a mais jovem ou nova (a segunda), em sua heterogeneidade; do outro, a mais antiga, igualmente heterogênea (a primeira).

Isto posto, a respeito da teoria arqueológica no cenário nacional, acredito que está cada vez mais difícil tentar inviabilizar a existência de múltiplas abordagens em Arqueologia, muito menos querer que prevaleça a idéia de ela ser uma ciência social que nada tem a ver com a atualidade - como se algum dia tivesse sido ou venha a ser neutra -, conforme assinalou S. Oliveira (2002, p. 49-64).

\section{Para onde caminha a arqueologia brasileira?}

Após todas as idéias apresentadas, uma pergunta vem à tona: afinal, o que estava acontecendo com a Arqueologia Brasileira no final do século $X X$ ? As respostas são múltiplas e difíceis de serem teoricamente equacionadas no calor da hora, porém vale a pena arriscar uma aproximação: a partir do processo de redemocratização do país e em clima de pós-modernidade (Harvey, 1992), a Arqueologia no Brasil caminhou para um momento de crise e situação de redefinição de sua identidade. Essas transformações também estão historicamente relacionadas com "os desdobramentos da globalização", conforme percebeu Gaspar (2000, p. 25), e sobretudo com a gradual "abertura das fronteiras institucionais e individuais, fazendo com que ocorra uma internacionalização dos saberes e das profissões", valendo-me aqui ainda da avaliação do perfil dos historiadores brasileiros feita por Kern (2000b, p. 6; ver também Kern, 2002, p. 122-124). Teve início, então, o processo da construção de uma outra realidade, da emergência paulatina de uma proposta de rompimento com todo tipo de isolamento acadêmico. Daí dizer que este é, com efeito, o atual momento da Arqueologia Brasileira, um tempo marcado por contrastes, tensões e conflitos de idéias, ideologias e forças políticas entre diferentes gerações, porém igualmente bastante fértil e plural em termos de produção científica.

Há, porém, que deixar claro que o processo de globalização apontado por Gaspar (2000) não deve ser visto apenas como uma forma de socialização de conhecimentos, mas também como uma estratégia política de dominação cultural e consumo de saberes gerados ou reinventados em países como os Estados Unidos, à luz de seus interesses hegemônicos no cenário mundial. Isto ocorre no contexto da chamada aceleração contemporânea, tratada por Milton 
Santos (1997). Daí perceber, por exemplo, as muitas influências da Arqueologia Estadunidense no Brasil, especialmente a partir da década de 1990, e ao fato de parte expressiva dos trabalhos publicados por arqueólogos latino-americanos ainda ser praticamente desconhecida para cientistas sociais de língua anglo-saxônica (J. Oliveira, 2002).

Hoje em dia, destarte, parece haver um certo entendimento de que a Arqueologia Brasileira vive "um momento rico e promissor da disciplina em nosso país", conforme recentemente frisaram Wüst et al. (1997 [2001], p. 5). Esta avaliação, contudo, contraria duas frases infelizes que Irmhild Wüst e Walter A. Neves teriam dito durante o debate As Perspectivas da Arqueologia Brasileira, ocorrido em São Paulo, no mês de abril de 2000, uma promoção do jornal Folha de S. Paulo (ver Nogueira, 2000). Primeira: "Do total produzido pela arqueologia brasileira, $99 \%$ podem ir para o lixo" (Irmhild Wüst). Segunda: "O melhor curso de pós-graduação no Brasil é o aeroporto de Cumbica" (Walter A. Neves). As duas falas foram duramente criticadas por vários arqueólogos brasileiros, muitos dos quais passaram por situações constrangedoras em seus locais de trabalho: mensagens eletrônicas foram encaminhadas ao referido jornal e a membros da Sociedade de Arqueologia Brasileira (SAB), a maioria protestando sobre o assunto e solicitando providências.

Na ocasião do debate, Pedro Paulo A. Funari, por sua vez, teria ponderado dizendo o seguinte: "A arqueologia brasileira agora está produzindo livros e artigos no exterior, passando a ser uma referência internacional". Esta última avaliação em tese foi a mais sensata, conseqüente e correta em relação às duas primeiras. Ocorre que atualmente alguns nomes da Arqueologia Brasileira têm conquistado reconhecimento nacional e internacional no estudo de certos objetos. Eis alguns exemplos: origens do povoamento préhistórico das Américas (Walter A. Neves e André Prous), pinturas rupestres (André Prous), Arqueologia Histórica e teorias arqueológicas (Pedro Paulo A. Funari), Arqueologia Histórica Missioneira (Arno A. Kern), pré-história amazônica (Eduardo G. Neves), Arqueologia Guarani (Francisco S. Noelli), dentre muitos outros.

Fica claro, portanto, que a ausência de um balanço mais refinado sobre a produção acadêmica e científica apresentada no âmbito da Arqueologia Brasileira, principalmente nos últimos quinze anos, em princípio tem levado alguns profissionais a pouco valorizarem o que vem sendo feito no país desde fins da década de 1980. Apesar disso tudo, a Folha de S. Paulo não deu espaço para réplicas. Neste caso em específico, o jornalista Salvador Nogueira 
(2000), autor da matéria Pesquisadores estão pessimistas com a arqueologia brasileira, publicou apenas alguns pequenos trechos do debate entre os arqueólogos, frases que devem ser avaliadas como pontuais e divergentes entre si, ao menos da maneira como vieram a público. Mesmo assim é fato que as ditas falas de Irmhild Wüst e Walter A. Neves causaram revolta e indignação entre profissionais de todas gerações e regiões do país, sobretudo pelo tom sectário e acientífico das críticas pronunciadas diante da grande imprensa.

Influenciada também pelos debates mundiais sobre processualismo e pós-processualismo, a nova geração vem se apresentando como a mais ousada e aquela que tem assumido uma postura de impulso vanguardista, ao meu ver precursora de um importante movimento de renovação dos estudos arqueológicos no país. Um exemplo disso é a divulgação do dossiê Antes de Cabral, organizado por Walter A. Neves (1999/2000a) e publicado na Revista USP, importante periódico científico do país, o qual contou com a colaboração de um grupo heterogêneo de jovens arqueólogos que elaborou uma das melhores, senão a melhor, síntese sobre Arqueologia e pré-história do Brasil até aquela data. Jovens arqueólogos, aliás, também têm sido a identificação e a auto-identificação de muitos profissionais pós-graduados a partir da década de 1990, como dito antes, termo este vulgarizado com mais intensidade a partir da VIII Reunião Científica da Sociedade de Arqueologia Brasileira, realizada em Porto Alegre, evento marcado por uma acirrada disputa política pela direção da SAB. Todavia, é equivocado pensar que uma nova geração de arqueólogos esteja limitada a uma determinada faixa etária, pois como disse José Honório Rodrigues:

"[...] uma geração é uma mudança de sentir e compreender a vida, oposta à maneira anterior, ou pelo menos, diferente dela. Nas gerações renovadoras aparecem sempre os mestres da transição, aqueles que, pela primeira vez, ensinam os novos caminhos. Sem eles a geração que representam e a história parariam, numa formação definitiva, sem possibilidade de renovação radical" (Rodrigues, 1978, p. 123).

Há ainda outros espaços de divulgação da produção científica da jovem geração, como é o caso da Coleção Arqueologia, publicada pela Edipucrs (Editora da PUCRS), importante veículo para a circulação de dissertações, teses e outros estudos acadêmicos; os trabalhos de Schaan (1997), Soares (1997), Symanski (1998) e Barcelos (2000) fazem parte da coleção e atestam a boa qualidade dos trabalhos que vêm sendo feitos no Sul do Brasil. Outros espa- 
ços de divulgação das pesquisas, sobretudo novas revistas ou novas fases de antigos periódicos científicos, vêm sendo criados a partir da década de 1990. Um outro bom exemplo dessa situação é a nova fase da Revista do CEPA, publicada pela Edunisc (Editora da Universidade de Santa Cruz do Sul), espaço que jovens arqueólogos sulistas passaram a ocupar com muita competência. Por outro lado, há ainda algumas revistas mais antigas que continuam fechadas, servindo basicamente à divulgação dos trabalhos de um único profissional ou de um grupo restrito de arqueólogos a ele ligado.

Portanto, parafraseando Acuto e Zarankin (1999, p. 13), avalio que é por tudo isso e por muito mais que jovens arqueólogos continuam seguindo sedentos, pois a sede faz parte da efetiva construção do saber científico e do comportamento de alguns cientistas, sem a qual não haveria mudanças de nuances ou transformações epistemológicas.

Neste sentido, enquanto as décadas de 1960 e 1970 ficaram fortemente marcadas por uma dose talvez exagerada de autodidatismo, empirismo, indutivismo e uma conseqüente falta de interesse por novos aportes teóricos, apesar da grande quantidade de pesquisas realizadas, algo que não foi monopólio da $\mathrm{Ar}$ queologia no Brasil, as de 1980 e 1990 testemunharam o surgimento de uma gradativa e crescente transformação rumo a uma Arqueologia Brasileira mais dedutiva, erudita, heurística, holística, plural, social e teoricamente mais aberta, preparada e diversificada. Esta é uma das explicações para a postura que jovens arqueólogos têm assumido, característica dos que almejam uma Arqueologia Brasileira para além-fronteiras e de padrão internacional, condição elementar para novas possibilidades de produzir, analisar e interpretar as sociedades humanas no tempo. Em outras palavras: se a geração mais antiga (a primeira) foi moder$n a$, a nova geração (a segunda) possui uma condição pós-moderna e se afirma na crítica à modernidade, em que pese saber que "nem sempre moderno tem significado necessariamente de novo, e antigo nem sempre tem significado o velho, o tradicional" (Azevedo, 1994, p. 17). Este é, com efeito, o vir-a-ser da Arqueologia Brasileira.

Isso posto, acredito que continua sendo válida a seguinte leitura que Philip Rahtz fez sobre as indissociáveis qualidades que todo arqueólogo precisar ter, a qual cito a seguir para finalizar este ensaio: 
"O que todo arqueólogo precisa é, não necessariamente nesta ordem, de um grande interesse pelo passado ou pela teoria da arqueologia, beirando as raias do fanatismo; uma capacidade de executar continuamente um trabalho difícil, em geral longe das condições ideais, seja no campo, na biblioteca ou no museu; uma alta margem de tolerância e aceitação para com os aborrecimentos; uma ativa, porém controlada, noção de ordem, padrão, processo e significados, uma imaginação visual e conceitual e uma ampla perspectiva cultural; e, de preferência, embora não obrigatoriamente, uma capacidade para se comunicar com outros seres humanos por escrito ou oralmente" (Rahtz, 1989, p. 58).

\section{Referências bibliográficas}

ACUTO, F. A.; ZARANKIN, A. Introducción: aun sedientos. In: ZARANKIN, A.; ACUTO, F. A. (Ed.). Sed Non Satiata. Teoria Social en la Arqueología Latinoamericana Contemporánea. Buenos Aires: Tridente, 1999, p. 7-15.

ARRUDA, J. J.; TENGARRINHA, J. M. Historiografia luso-brasileira contemporânea. Bauru: Edusc, 1999.

AZEVEDO, N. P. de. Arqueologia e modernidade. Revista de Arqueologia, São Paulo, n. 8, v. 1, p. 17-23, 1994.

BARCELOS, A. H. F. Espaço e Arqueologia nas missões jesuitas. Porto Alegre: Edipucrs, 2000.

BARRETO, C. Brazilian Archaeology from a Brazilian perspective. Antiquity, Cambridge, n. 72, p. 573-581, 1998.

- Arqueologia Brasileira: uma perspectiva histórica e comparada. Revista do Museu de Arqueologia e Etnologia (Série Suplemento), São Paulo, n. 3, p. 201-212, 1999.

. A construção de um passado pré-colonial: uma breve História da Arqueologia Brasileira. Revista USP, São Paulo, n. 44, v. 1, p. 32-51, 1999/2000.

BLOCH, M. Introdução à História. 5. ed. Trad. de M. Manuel \& R. Grácio. Lisboa: Europa-América, 1987.

BOSI, A. A importância da universidade pública. Ciência Hoje, Rio de Janeiro, n. 28 , v. 165 , p. $42-48,2000$.

CARDOSO, C. F. S. Uma introdução à História. 10. ed. São Paulo: Brasiliense, 1984.

BRIGNOLI, H. P. Os métodos da História. 5. ed. Trad. de J. Maia. Rio de Janeiro: Graal, 1990.

COLLINGWOOD, R. G. A idéia de História. Trad. de A. Freire. Lisboa: Presença, 1981.

DIAS, A. S. Repensando a Tradição Umbu a partir de um estudo de caso. Dissertação de Mestrado. Porto Alegre: PUCRS, 1994. 
DIAS JÚNIOR, O. F. A contribuição de Betty Meggers para a Arqueologia Préhistórica da América do Sul. Boletim do Instituto de Arqueologia Brasileira, Rio de Janeiro, n. 10, p. 7-18, 1997.

FAUSTO, B. História do Brasil. 6. ed. São Paulo: Edusp/FDE, 1999.

FERNANDES, F. A transição programada: o período pós-constitucional. São Paulo: Cortez, 1990.

FERREIRA, L. M. Vestígios de Civilização: o Instituto Histórico e Geográfico Brasileiro e a construção da Arqueologia Imperial (1838-1870). Revista de História Regional, Ponta Grossa, n. 4, v. 1, p. 9-36, 1999.

. Arqueologia e geoestratégia: as fronteiras imperiais e o uso das fontes arqueológicas (1838-1877). Varia Historia, Belo Horizonte, n. 24, p. 149-171, 2001.

FOGAÇA, E. Teoria e método na Arqueologia Brasileira (ou O Demônio de Maxwell). In SOUZA, S. M. F. M. de (Org.). Anais do IX Congresso da Sociedade de Arqueologia Brasileira. Rio de Janeiro: SAB, 2000. (cd-rom).

FUNARI, P. P. A. Arqueologia. São Paulo: Ática, 1988.

- Brazilian Archaeology and World Archaeology: some remarks. Word Archaeological Bulletin, n. 3, p. 60-68, 1989.

- La Arqueología en Brasil: política y academia en una encrucijada. In: POLITIS, G. G. (Ed.). Arqueología en América Latina hoy. Bogotá: Biblioteca Banco Popular, p. 57-69, 1992.

- Memória histórica e cultura material. Revista Brasileira de História, São Paulo, n. 13, v. 25-26, p. 17-31, 1993a.

Algumas reflexões sobre a relação entre a teoria e a práxis na Arqueologia. Palestra proferida no VII Simpósio Sul-riograndense de Arqueologia e I Fórum de Arqueologia do Cone Sul. Taquara, 1993b [3/4/1993].

Arte e Arqueologia, Campinas, n. 1, p. 23-41, 1994a.

. Paulo Duarte e Instituto de Pré-história: documentos inéditos. Idéias, Campinas, n. 1, v. 1, p. 155-179, 1994 b.

Arqueologia, História e Arqueologia Histórica no contexto Sulamericano. In: FUNARI, P. P. A. (Org.). Cultura Material e Arqueologia Histórica. Campinas: IFCH-UNICAMP, p. 7-34, 1998a.

— Teorias arqueológicas na América do Sul. Campinas: EdUnicamp, 1998b.

- Brazilian Archaeology: a reappraisal. In: POLITIS, G. G.; ALBERTI, B. Archaeology in Latin America. London: Routledge, p. 17-37, 1999.

1, p. $74-85,1999 / 2000$.

. Pedro Paulo A. Funari, publicações sobre Arqueologia. São Paulo, 2001. (não publicado) 
GASPAR, M. D. [Madu Gaspar]. Sambaqui: Arqueologia no litoral brasileiro. Rio de Janeiro: Jorge Zahar, 2000.

HARVEY, D. Condição pós-moderna: uma pesquisa sobre as origens da mudança cultural. 5. ed. Trad. de A. V. Sobral e M. S. Gonçalves. São Paulo: Loyola, 1992.

HILL, J. N. Archaeology and the accumulation of knowledge. In: PREUCEL, R. W. (Ed.). Processual and Postprocessual Archaeologies: multiple ways of knowing the past. Illinois, The Southern Illinois University at Carbondale, p. 42-53, 1991.

HOBSBAWM, E. Sobre História: Ensaios. 2. ed. Trad. de C. K. Moreira. São Paulo: Companhia das Letras, 1998.

IANNI, O. A idéia de Brasil moderno. São Paulo: Brasiliense, 1992.

IGLÉSIAS, F. A História no Brasil. In: FERRI, M. G.; MOTOYAMA, S. (Coord.). História das Ciências no Brasil. São Paulo: Epu/Edusp, p. 265-301, 1979.

KERN, A. A. O Sítio-escola Internacional do Pós-graduação em História da PUCRS: importância e caracterização. Revista de Arqueologia, São Paulo, n. 8, v. 2, p. 89-98, 1994.

. A Arqueologia no Pós-graduação em História da PUCRS. In SOUZA, S. M. F. M. de (Org.). Anais do IX Congresso da Sociedade de Arqueologia Brasilei$r a$. Rio de Janeiro: SAB, 2000a. (cd-rom).

- O perfil dos historiadores no novo milênio. Revista da SBPH, Curitiba, n. 19 , p. $4-17,2000$ b.

- O futuro do passado: os arqueólogos do novo milênio. Trabalhos de Antropologia e Etnologia, Porto, n. 42, v. 1-2, p. 115-136.

KIPNIS, R. et al. (Org.). Bibliografia da Arqueologia Brasileira. Arquivos do Museu de História Natural, Belo Horizonte, n. 15-16, p. i-x/1-313, 1994-1995.

LANGER, J. Mitos arqueológicos e poder. Clio (Série Arqueológica), Recife, n. 12, p. 109-125, 1997a.

-O megalitismo na pré-história brasileira. Revista de Arqueologia, São Paulo, n. 10, p. 89-106, 1997b.

LAPA, J. R. do A. Historiografia Brasileira contemporânea: a História em questão. $2^{\mathrm{a}}$ ed. Petrópolis: Vozes, 1981.

- História e Historiografia do Brasil Pós-64. Rio de Janeiro: Paz e Terra, 1985.

LATHRAP, D. W. O alto Amazonas. Trad. de M. A. Garcia. Lisboa: Verbo, 1975.

LE GOFF, J. A História Nova. In: LE GOFF, J. A História Nova. 2. ed. Trad. de E. Brandão. São Paulo: Martins Fontes, p. 25-64, 1993.

LEITE, M. O país sem pré-história. Folha de S. Paulo, São Paulo, Mais!, 19 mar., p. 1-12, 2000. 
LIMA, T. A. Arqueologia Histórica no Brasil: balanço biográfico (1960-1991). Anais do Museu Paulista (Nova Série), São Paulo, n. 1, p. 225-262, 1993.

. Teoria e método na Arqueologia Brasileira: avaliação e perspectivas. In SOUZA, S. M. F. M. de (Org.). Anais do IX Congresso da Sociedade de Arqueologia Brasileira. Rio de Janeiro: SAB, 2000. (cd-rom).

— ; SILVA, R. C. P. da. 1898-1998: a Pré-história Brasileira em cem anos de livros didáticos. Fronteiras, Campo Grande, n. 3, v. 6, p. 91-134, 1999.

LUMBRERAS, L. G. La arqueología sudamericana: três décadas. In: MEGGERS, B. J. (Ed.). Prehistoria Sudamericana: nuevas perspectivas. Santiago de Chile: Editorial Universitaria; Washington: Taraxacum, p. 27-32, 1992.

LYMAN, R. L. et al. The rise and fall of Culture History. New York: Plenum Press, 1997.

MARTIN, G. Pré-história do Nordeste do Brasil. Recife: EDUFPE, 1996.

MEGGERS, B. J. Advances in Brazilian archaeology. American Antiquity, Washington, n. 50, v. 2, p. 364-373, 1985.

—. Desenvolvimento da Arqueologia Brasileira, 1935-1985: uma visão pessoal. Trad. de M. B. de Almeida. In: CARVALHO, E. T. de. Pesquisa do Passado: Arqueologia no Brasil. Rio de Janeiro: IAB, p. 149-154, 1987a.

— . Amazônia - a ilusão de um paraíso. 2. ed. Trad. de M. Y. Linhares. São Paulo: Edusp; Belo Horizonte: Itatiaia, 1987b.

- Desenvolvimento cultural pré-histórico nas terras baixas tropicais da América do Sul: Amazonas e Orinoco. Trad. de J. E. de Oliveira. Fronteiras, Campo Grande, n. 2, v. 4, 9-38, 1998a.

- Evolución y difusión cultural. Enfoques teóricos para la investigación arqueológica I. Quito: Abya-Yala, 1998b.

- Ecología y Biogeografía de la Amazonía. Enfoques teóricos para la investigación arqueológica II. Quito: Abya-Yala, 1999.

MELTZER, D. J. Paradigms and the nature of change in American Archaeology. American Antiquity, Washington, n. 44, v. 4, p. 644-657, 1979.

MOBERG, C.-A. Introdução à Arqueologia. Trad. de M. R. H. da Silva. Lisboa: Edições 70, 1986.

NEVES, E. G. Duas interpretações para explicar a ocupação pré-histórica na Amazônia. In: TENÓRIO, M. C. (Org.). Pré-história da Terra Brasilis. Rio de Janeiro: EdUFRJ, p. 359-367, 1999.

- O velho e o novo na Arqueologia Amazônica. Revista USP, São Paulo, n. 44 , v. 1 , p. $86-111,1999 / 2000$.

NEVES, W. A. Arqueologia Brasileira: algumas considerações. Boletim do Museu Paraense Emílio Goeldi (Série Antropologia), Belém, n. 2, p. 200-205, 1988.

. (Org.). Biologia e Ecologia Humana na Amazônia: avaliação e perspectivas. Belém: Museu Paraense Emílio Goeldi, 1989. 
- (Org.). Origens, adaptações e diversidade biológica do homem nativo da Amazônia. Belém: Museu Paraense Emílio Goeldi, 1991. 1999/2000a.

(Org.). Antes de Cabral. Revista USP, São Paulo, n. 44, v. 1-2,

- Antes de Cabral: a Arqueologia e a sociodiversidade no passado. Revista USP, São Paulo, n. 44, v. 2, p. 6-9, 1999/2000b.

NOGUEIRA, S. Pesquisadores estão pessimistas com a Arqueologia Brasileira. Folha de S. Paulo, São Paulo, 19 abr., 2000.

OLIVEIRA, J. E. de. Da Pré-história à História Indígena: (re)pensando a Arqueologia e os povos canoeiros do Pantanal. Tese de Doutorado. Porto Alegre: FFCHPUCRS, 2002.

OLIVEIRA, S. N. A Arqueologia Guarani: construção e desconstrução da identidade indigena. Dissertação de Mestrado. Campinas: UNICAMP, 2002.

PROUS, A. Arqueologia Brasileira. Brasília: EdUnB, 1992.

- L'Archéologie Brésilienne aujourd'hui: problèmes et tendances. In: LÉVÊQUE, P. et al. (Ed.). Recherches Brésiliennes. Annales Littéraires de l' Université de Besançon, Paris, n. 130, p. 9-43, 1994.

RAHTZ, P. Convite à Arqueologia. Trad. de L. O. C. Lemos. Rio de Janeiro: Imago, 1989.

REIS, E. P. et al. As ciências sociais nos últimos 20 anos: três perspectivas. Revista Brasileira de Ciências Sociais, São Paulo, n. 12, v. 35, p. 1-24, 1997.

RODRIGUES, J. H. Teoria da História do Brasil: introdução metodológica. 4. ed. São Paulo: Companhia Editora Nacional/MEC, 1978.

ROOSEVELT, A. C. Determinismo ecológico na interpretação do desenvolvimento social indígena da Amazônia. In: NEVES, W. A. (Org.). Origens, adaptações e diversidade biológica do homem nativo da Amazônia. Belém: Museu Paraense Emílio Goeldi, p. 103-141, 1991.

- Arqueologia Amazônica. Trad. de J. M. Monteiro. In: CUNHA, M. C. da (Org.). História dos índios no Brasil. São Paulo: Cia das Letras/SMC/Fapesp, p. 53-86, 1992.

- O povoamento das Américas: o panorama brasileiro. In: TENÓRIO, M. C. (Org.). Pré-história da Terra Brasilis. Rio de Janeiro: EdUFRJ, p. 35-50, 1999.

SANTOS, M. do C. M. M. dos. A problemática do levantamento arqueológico na avaliação de impacto ambiental. Dissertação de Mestrado. São Paulo: USP, 2001.

SANTOS, M. A aceleração contemporânea: tempo, mundo e espaço mundo. In: SANTOS, M. S. et al. (Org.). O novo mapa do mundo: fim de século e globalização. 3. ed. São Paulo, p. 15-22, 1997.

SCHAAN, D. P. A linguagem iconográfica da cerâmica Marajoara: um estudo da arte pré-histórica na Ilha de Marajó - Brasil (400-1300 AD). Porto Alegre: Edipucrs, 1997. 
SCHMITZ, P. I. Brazil: tendencies and growth. In OYUELA-CAYCEDO, A. (Ed.). History of Latin American Archaeology. Avebury: Aldershot, p. 22-35, 1994.

SILVA, F. C. T. da. A modernização autoritária: do golpe militar à redemocratização (1964/1984). In: LINHARES, M. Y. (Org.). História geral do Brasil. Rio de Janeiro: Campus, p. 273-303, 1990.

SOARES, A. L. R. Guarani: organização social e Arqueologia. Porto Alegre: Edipucrs, 1997.

SOCIEDADE DE ARQUEOLOGIA BRASILEIRA. Diretrizes para a Arqueologia Brasileira: Documento de Santa Cruz do Sul. Revista do CEPA, Santa Cruz do Sul, n. 17, v. 20, p. 457-463, 1989.

SOUZA, A. M. de. História da Arqueologia Brasileira. Pesquisas (Série Antropologia), São Leopoldo, n. 46, p. 1-157, 1991.

SYMANSKI, L. C. P. Espaço privado e vida material em Porto Alegre no século XIX. Porto Alegre: Edipucrs, 1998.

TRIGGER, B. G. Historia del pensamiento arqueológico. Trad. de I. G. Trócoli. Barcelona: Crítica, 1992.

VELHO, O. G. Processos sociais no Brasil pós-64: as ciências sociais. In: SORJ, B.; ALMEIDA, M. H. T. de. (Org.). Sociedade e política no Brasil pós-64. $2^{\mathrm{a}}$ ed. São Paulo: Brasiliense, p. 240-261, 1984.

WILLEY, G. R.; PHILliPS, P. Method and theory in American Archaeology. Chicago: The University of Chicago Press, 1958.

WÜST, I. et al. Editorial. Revista de Arqueologia, São Paulo, n. 10, p. 5, 1997. 